\title{
RBEP
}

\section{Políticas públicas de ações afirmativas para ingresso na educação superior se justificam no Brasil?}

Celia Maria Haas

Milton Linhares

\section{Resumo}

Tem por finalidade analisar o sistema de cotas, uma das ações afirmativas de políticas públicas que visam a assegurar o ingresso, no ensino superior, de segmentos sociais discriminados. No Brasil, a gritante desigualdade social, o preconceito, a baixa qualidade da educação oferecida nas escolas públicas de ensino fundamental e médio, a pobreza e a marginalização aprofundam e perpetuam a discriminação e dificultam o acesso ao ensino superior. Neste contexto, o sistema de cotas, desde que não baseado exclusivamente no critério de raça, sem ferir a autonomia universitária e com mecanismos para garantir a aprendizagem e permanência dos cotistas, pode contribuir para resgatar a dignidade da pessoa humana, reparar injustiças históricas contra determinado grupo social e concretizar o preceito constitucional de igualdade de direitos e de oportunidades para todos os cidadãos.

Palavras-chave: políticas públicas; ações afirmativas; responsabilidade social; cotas; universidade; educação. 


\section{Abstract \\ Are affirmative action public policies for higher education admission justified in Brazil?}

This paper examines the quotas system, affirmative action from a public policy aimed at ensuring access to higher education for broken down social segments. In Brazil, the glaring social inequalities, many prejudices, the low quality of education offered in public schools of basic and secondary education, the poverty and marginalization deepen and perpetuate the discrimination making difficult the access to higher education. In this context, the system of quotas, since that is not based only on the criterion of race, without hurting the university autonomy and with mechanisms to ensure the learning and shareholder's permanence, can help rescue the dignity of the human person, repairing historical injustices against a certain social group and implement the constitutional provision of equal rights and opportunities for all citizens.

Keywords: public policies; affirmative action; social responsibility; quotas; university; education.

\section{Introdução}

Este texto tem por objetivo discutir a implantação de reserva de vagas no ensino superior brasileiro mediante o sistema de cotas, especificamente a iniciativa para a concretização dessa política nas universidades públicas.

Inicialmente, são feitas considerações sobre o polêmico debate nacional das políticas públicas de ações afirmativas visando a integrar socialmente indivíduos pertencentes a grupos étnico-raciais desfavorecidos. São registradas, também, as iniciativas de implantação, no Brasil, de políticas públicas voltadas à inclusão de negros e pardos no sistema de ensino superior, sua complexidade e suas consequências no contexto da diversidade nacional, com base em indicadores da desigualdade entre brancos e negros na renda e no tempo médio de escolaridade.

Os aspectos legais, constitucionais e educacionais do sistema de cotas são tratados, no Brasil, sob o enfoque da relação com o princípio constitucional da igualdade. A proibição da discriminação e a adoção de medidas concretas que possam reduzir as desigualdades sociais são analisadas com base em argumentos e interpretações de juristas e educadores.

Também são ressaltados os posicionamentos contrários e os favoráveis às cotas no ensino superior público, manifestados, desde o 
início das discussões, por intelectuais, professores, advogados e jornalistas especializados em educação, entre outros.

O direito à educação, garantido na Constituição Brasileira de 1988 como dever do Estado, e a conceituação do termo minoria são contextualizados de modo a assegurar quão importantes são na definição de posições públicas do governo federal em relação à defesa ou repúdio das ações afirmativas por meio de cotas na universidade.

Por fim, são analisados dois casos de implantação de reserva de vagas por intermédio do sistema de cotas para candidatos afrodescendentes e indígenas, a saber: no Distrito Federal, Universidade de Brasília (UnB); e no Estado do Rio de Janeiro, Universidade do Estado do Rio de Janeiro (Uerj) e Universidade Estadual do Norte Fluminense Darcy Ribeiro (Uenf). A análise comparativa destes dois casos e as contribuições para a ampliação do debate são pontos fundamentais para as considerações finais.

Cabe registrar que o Congresso Nacional aprovou, em caráter conclusivo, na data de 20 de novembro de 2008, o Projeto de Lei $n^{\circ}$ 3.627/2004, que determina a todas as instituições públicas federais de ensino superior reservarem $50 \%$ de suas vagas a candidatos que tenham cursado integralmente o ensino médio em escolas públicas (Brasil, 2004).

Segundo o texto aprovado, nessa porcentagem deverá haver cotas para autodeclarados pretos, pardos e indígenas, em percentuais a serem definidos de acordo com as proporções desses grupos em cada unidade federativa, apontados por dados do Censo do Instituto Brasileiro de Geografia e Estatística (IBGE). O projeto prevê ainda que a reserva de vagas seja aplicada em cada curso e em cada turno das universidades, e estas terão quatro anos para se adaptarem às novas regras.

Por outro lado, tramita no Congresso Nacional o Projeto de Lei $\mathrm{n}^{\circ}$ 7.200/2006, do Poder Executivo, que prevê a implantação do sistema de cotas nas universidades públicas federais, dando prazo de dez anos para que as instituições atingidas pela nova regra possam se adaptar (Brasil, 2006).

\section{A pesquisa}

Apesar das discussões, a nova Lei Orgânica da Educação Superior proposta pelo Ministério da Educação em dezembro de 2006 está abandonada. Portanto, a reforma estrutural no sistema federal de ensino superior tem sido provocada por outros caminhos e atalhos que refletem diretamente nas universidades públicas brasileiras. Naquele cenário, e hoje mais fortemente, a problemática da implantação de políticas de ação afirmativa - o sistema de cotas (étnicas, socioeconômicas, religiosas, de gênero) - como uma das modalidades de acesso ao ensino superior tem sido mobilizadora de amplos debates.

As ações afirmativas situam-se no cerne do debate educacional e constitucional e interferem em problemas que remontam às questões da diversidade cultural, da inclusão social e, sobretudo, da cidadania no Brasil. Esse debate, entretanto, está longe de gerar consenso, embora 
já existam casos de implantação do sistema de cotas para o acesso de estudantes nos processos seletivos de algumas universidades públicas, como são os casos da UnB, da Uerj e da Uenf.

No Brasil, a apresentação de projetos com o objetivo de estabelecer em lei garantias mínimas para o acesso da população afrodescendente e indígena ao ensino superior incorpora as mais diversas tendências ideológicas, porém busca, de modo geral, mitigar a incontestável desigualdade social brasileira, visando a atacar e corrigir distorções que se encontram numa das causas dessa desigualdade - a maneira como nosso sistema educacional está estruturado.

Embora esses projetos tenham sido objeto de polêmica e de críticas por parte da sociedade brasileira, quase todos buscaram, de maneira geral, minimizar a desigualdade instalada no sistema educacional do País e promover a concretização do princípio constitucional da igualdade prescrito na Constituição Federal de 1988, que, em seu art. 5, caput, estabelece: "Todos são iguais perante a lei, sem distinção de qualquer natureza, garantindo-se aos brasileiros e aos estrangeiros residentes no País a inviolabilidade do direito à vida, à liberdade, à segurança e à propriedade [...]" (Brasil, 2010).

Ressalte-se ainda que, nas justificativas apresentadas nos projetos referidos, encontra-se a importância atribuída à Educação, vista como um instrumento de ascensão social e de desenvolvimento do País.

A análise e o estudo sistemático da implantação do sistema de cotas pelas universidades públicas justificam-se diante dos dados estatísticos referentes ao restrito acesso da população brasileira ao ensino superior, especificamente da situação desfavorável do acesso das populações afrodescendente e indígena à Educação e, sobretudo, da incompatibilidade dessa situação com a ideia de igualdade, justiça e democracia prescrita na legislação brasileira.

Esse quadro de profundas desigualdades sociais permitiu a existência de um sistema perverso que, segundo bem observa Gomes (2003), imputou a negros e pobres uma educação de qualidade inferior, dedicando recursos materiais, humanos e financeiros voltados à educação de todos os brasileiros a um pequeno contingente da população que detém a hegemonia política e socioeconômica do País - a elite branca.

A relevância do tema expõe o papel da universidade brasileira e de sua responsabilidade diante do grave problema da exclusão educacional, da extrema desigualdade social e da discriminação que permeiam as relações socioeconômicas no Brasil.

Ressalte-se que, no Brasil, a principal referência para discussão sobre políticas públicas voltadas à implantação de ações afirmativas, especialmente à implantação do sistema de cotas na educação superior, é o modelo norte-americano, o maior sistema de ensino superior do mundo.

A efetiva implantação do sistema de cotas pelas universidades públicas envolve a ampla participação da comunidade educacional e deve ser precedida por discussões nos respectivos Conselhos Universitários, não podendo, todavia, ser realizada de maneira autoritária e arbitrária por parte do Estado. 
Se a sociedade almeja se construir de forma fraterna, mais justa e solidária, entende-se que poderá atingir tais objetivos a partir do acesso ao conhecimento por intermédio da Educação. Desta forma, a presente análise sobre a implantação do sistema de cotas pretende contribuir com o debate referente à adoção das políticas de ações afirmativas pelo Estado, sem a pretensão de esgotar aqui a discussão e análise do tema.

\title{
Metodologia
}

A presente análise focaliza o conceito de ação afirmativa e suas origens históricas, os sistemas de cotas e suas aplicações na área da educação, o princípio da igualdade sob aspectos jurídicos e constitucionais, tendo como premissa o fato de a instituição das cotas, para o acesso de grupos discriminados ao ensino superior, encontrar conexão com condições socioeconômicas, educacionais e normas específicas do Estado de Direito. Por conseguinte, a correlação de saberes remete à necessidade de uma abordagem interdisciplinar correspondente, segundo Japiassú e Marcondes (1996, p. 145),

\begin{abstract}
a uma nova etapa do desenvolvimento do conhecimento científico e de sua visão epistemológica, que exige que as disciplinas, em seu processo constante e desejável de interpenetração, fecundem-se cada vez mais reciprocamente; a interdisciplinaridade é um método de pesquisa e de ensino suscetível de fazer com que as disciplinas interajam entre si.
\end{abstract}

De acordo com dados do Censo da Educação Superior do ano de 2009, realizado pelo Instituto Nacional de Estudos e Pesquisas Educacionais Anísio Teixeira (Inep), em relação à graduação presencial das instituições públicas de ensino superior, do universo de ingressantes por processo seletivo, 36,2 mil ocorreram por conta de reserva de vagas. Entre os tipos de programas de reserva de vagas coletados (étnico, procedente de ensino público, social/renda familiar, pessoa com deficiência e outros), o destaque ficou com o que se destina a alunos procedentes do ensino público (69\%), seguido do relacionado com identidade étnica, com 25\% (Brasil. Inep, 2010).

Dados como os apresentados forçam a visualizar essas instituições por outros ângulos: de um lado, por sua função republicana de buscar o interesse público e o bem comum, e, de outro, pela dificuldade em atender ao preceito constitucional de oferecer educação a todos os cidadãos, com gratuidade e qualidade.

Diante dessas duas situações vividas pela universidade pública brasileira, que se complementam, a adoção de políticas de ações afirmativas por cotas pode contribuir para minimizar a dificuldade de seus gestores em administrar o problema da exclusão educacional de minorias historicamente discriminadas, além de atentar para os interesses desses grupos sem perder de vista os objetivos do Estado como mantenedor constitucional da educação pública com qualidade. 
Quanto ao referencial documental e teórico que fundamentou o presente artigo, partiu-se da leitura de fontes doutrinárias e documentais e da interpretação de dois modelos de sistemas de cotas implantados em universidades públicas perante a autonomia universitária constitucional e demais instrumentos legais. A análise dos dados estatísticos sobre educação e renda de jovens brancos e negros em idade universitária permitiu correlacionar a realidade das necessidades de políticas públicas de inclusão. Foram relevantes as colaborações interdisciplinares de outras áreas, como a do Direito, tendo em vista as manifestações de educadores, juristas e magistrados em questões que envolvem a legalidade da adoção de ações afirmativas pelo sistema de cotas em universidades públicas.

Houve duas principais motivações: a contribuição com o debate sobre as políticas públicas de educação, em especial aquelas voltadas para a inclusão de grupos excluídos do cenário da educação superior no Brasil, e a análise de dois casos de implantação do sistema de acesso ao ensino superior em universidades públicas por cotas - duas universidades do Rio de Janeiro e uma do Distrito Federal -, que, contudo, foram efetivados por encaminhamentos distintos e que mereceram observação.

\section{A implantação do sistema de cotas nas universidades públicas brasileiras}

A instituição da reserva de vagas para o acesso de determinado grupo de pessoas ao ensino superior nas universidades públicas pelo sistema de cotas indica a necessidade atual de se buscar caminhos de combate à exclusão educacional dos indivíduos pertencentes àquele grupo no referido nível de ensino. A medida acaba por forçar a sociedade a reconhecer o problema da desigualdade. Silva (2003, p. 20-21) explica:

A ação afirmativa é uma iniciativa essencial de promoção da igualdade [cujo principal objetivo] para as pessoas negras é combater o racismo e seus efeitos duradouros de ordem psicológica, além de introduzir mudanças de ordem cultural e de convivência entre os chamados diferentes.

Segundo a autora, "a questão da convivência entre os(as) diferentes como introdutora de mudanças de ordem estrutural só faz sentido quando se desconstroem as estruturas da desigualdade" (Silva, 2003, p. 20).

Estudo do Instituto de Pesquisa Econômica Aplicada (Ipea), de 2001, apontou que menos de $2 \%$ de estudantes negros(as) estão matriculados(as) nas instituições universitárias públicas e particulares, sendo que, deste grupo, somente $15 \%$ concluem o curso superior.

Henriques (2002, p. 39-41), pesquisador do Ipea, constata que o tempo de escolaridade sob a ótica do recorte racial de um jovem brasileiro negro com 25 anos de idade gira em torno de 6,1 anos de estudo; um jovem branco da mesma idade tem cerca de 8,4 anos de estudo. $O$ diferencial é de 2,3 anos de estudo em favor do jovem branco. 
Dados apresentados pela Pesquisa Nacional por Amostra de Domicílios (Pnad/IBGE) de 2008 ratificam o caráter estrutural das desigualdades raciais no Brasil, já que a média do tempo de estudo de brancos com mais de 15 anos é de 8,1 anos de estudo, enquanto negros e pardos apresentam 6,4 anos. Quanto à comparação do número de matrículas no ensino superior, dados da mesma pesquisa apontam que 57,9\% dos estudantes universitários brasileiros são brancos, enquanto pretos e pardos representam $28,9 \%$ do número de matrículas.

Há que se considerar uma latente situação de desigualdade na educação, no Brasil, particularmente no ensino superior, como consequência da ausência de políticas públicas voltadas especificamente para a implantação de ações afirmativas neste segmento. Não há como garantir que, ao adotá-las, o Brasil iniciará o caminho para o fim dessa desigualdade.

Corrobora esta afirmação o vigoroso e rico estudo elaborado por Sowell (2004) sobre a implantação das ações afirmativas ao redor do mundo, ao afirmar que os argumentos pró e contra as ações afirmativas tendem a invocar somente a história e tradições claramente americanas. No entanto, tratamentos preferenciais e sistema de cotas existem em outros países com histórias e tradições totalmente diferentes e, em alguns casos, implantados há muito mais tempo que nos Estados Unidos.

\section{Conceito de ações afirmativas}

O termo foi empregado pela primeira vez pelo então presidente americano Lyndon Johnson na Howard University, em 1965, passando a significar a exigência de favorecimento de algumas minorias socialmente inferiorizadas e juridicamente desigualadas por preconceitos histórica e culturalmente fixados. Há, porém, quem rebata este entendimento.

Embora a maioria dos autores cite o famoso discurso proferido pelo Presidente Lyndon Johnson na Howard University, em 1965, como sendo a primeira vez que a ação afirmativa teria aparecido no léxico oficial americano, a verdade é que o instituto resulta das diversas tentativas de inserção jurídica dos negros na sociedade, levada a efeito desde a guerra civil. Vários presidentes tomaram iniciativas de medidas visando à integração dos negros, de Franklin Roosevelt a John Kennedy, tendo este último, inclusive, editado a Executive Order no 10.925, de 6 de março de 1963, que cunhou a expressão "affirmative action". Por outro lado, o próprio Estatuto dos Direitos Civis, que data de 1964, na sua Seção 706 (g), faz alusão ao tema (Gomes, 2001, p. 57-58).

De acordo com essa Executive Order, nos contratos celebrados com o governo federal, como aponta Menezes (2001), o contratante não poderia discriminar nenhum funcionário ou candidato a emprego devido à raça, credo, cor ou nacionalidade. O contratante deveria adotar a ação afirmativa para assegurar que os candidatos fossem empregados e tratados durante o emprego sem consideração a sua raça, seu credo, sua cor ou nacionalidade. 
A introdução das políticas públicas de ações afirmativas representou a mudança de postura do Estado norte-americano, que, em nome da neutralidade, aplicava suas políticas governamentais indistintamente, ignorando a importância de fatores como sexo, raça, cor ou nacionalidade. Por outro lado, ao adotá-las, o Estado passaria a levar em consideração tais critérios.

Inicialmente, as ações afirmativas definir-se-iam como encorajamento do Estado a que as pessoas com poder decisório na esfera pública e, também, no setor privado levassem em consideração, nas suas decisões, os fatores supracitados quanto ao acesso ao mercado de trabalho e à educação, quais sejam: sexo, raça, cor e origem nacional das pessoas. Dessa forma, a referida ação deveria apresentar um caráter temporário num âmbito e escopo restritos.

Neste sentido, Taylor (1998, p. 60) afirma que se trata no mínimo de ingenuidade acreditar que as ações afirmativas se constituem medidas temporárias, visto que o aspecto fundamentador dessas medidas é justamente o reconhecimento da identidade cultural dos grupos historicamente excluídos, que, ao serem reconhecidos e afirmados em suas identidades peculiares, não aceitarão perder esse diferencial positivo que são as medidas componentes das políticas de ação afirmativa.

Em sentido contrário, constata-se em Dworkin (2001) o posicionamento favorável de que as medidas de ações afirmativas apresentam, entretanto, caráter provisório, ao considerar que elas devem fazer uso apenas transitório dos critérios raciais, com o objetivo de possibilitar um grau de cidadania mínima aos excluídos, de maneira que estes atinjam condições de serem efetivamente beneficiados por políticas públicas mais gerais, as quais, por sua vez, não são racialmente orientadas.

No Brasil, embora a ação afirmativa seja desconhecida da grande maioria da sociedade, o assunto começa a ser explorado no campo acadêmico, cujo debate em torno da temática tende a se intensificar. A própria controvérsia gerada por esta discussão indica a importância do tema não somente para a comunidade acadêmica, mas para toda a sociedade, pois se vê uma confusão de ideias e expressões frequentemente usadas como sinônimas: política de cotas, políticas compensatórias, política de reparação, política de promoção de igualdade, política antirracista, ou ainda, política de engajamento, política da diversidade ou política do multiculturalismo.

Neste aspecto, cabe ressaltar que países etnicamente diversificados como o Brasil, ainda que mantenham a discussão sobre a necessidade da adoção de políticas de ações afirmativas, precisam se definir quanto ao caráter temporário dessas iniciativas. Se as medidas que contribuem para a inclusão de sujeitos e seus componentes culturais na sociedade não tiverem prazos determinados poderão gerar novas e graves formas de preconceito de uns sobre outros grupos, fomentando atitudes racistas e estigmatizando os indivíduos beneficiados.

Assim, o significado do termo ação afirmativa gera inúmeras conotações, além de abranger um grande número de práticas. 
Ação afirmativa é um termo de amplo alcance que designa o conjunto de estratégias, iniciativas ou políticas que visam favorecer grupos ou segmentos sociais que se encontram em piores condições de competição em qualquer sociedade em razão, na maior parte das vezes, da prática de discriminação[ões] negativas, sejam elas presentes ou passadas (Menezes, 2001, p. 27).

Pode-se asseverar que são medidas especiais que buscam eliminar os desequilíbrios existentes entre determinadas categorias sociais até que sejam neutralizados, o que se realiza com providências efetivas em favor daquelas categorias que se encontram em posições desvantajosas.

Sendo assim, as ações afirmativas se constituem instrumentos de concretização da igualdade material. Neste sentido são, portanto, políticas públicas que dão preferência a segmentos sociais marginalizados no acesso aos direitos sociais, sobretudo à educação e ao mercado de trabalho.

Claro está até aqui que a sociedade que pretende se organizar como fraterna, mais justa e solidária precisa agir de maneira continuada, por intermédio do Estado, em busca de políticas de ações afirmativas.

Segundo Santos (1999), a finalidade das ações afirmativas é eliminar as desigualdades historicamente acumuladas, garantindo a igualdade de oportunidades e de tratamento, bem como compensar perdas provocadas pela discriminação e marginalização decorrentes de motivos raciais, étnicos, religiosos, de gênero e outros.

De acordo com os autores até aqui citados, existem por trás da ideia da ação afirmativa alguns objetivos, a saber:

a) Necessidade de se combater a discriminação que ocorre em certos espaços da sociedade;

b) Necessidade de se reduzir a desigualdade que atinge certos grupos, por exemplo, aquele marcado pela questão de raça ou gênero;

c) Transformação social;

d) Finalidade de acesso à escola e ao mercado de trabalho; e

e) Finalidade da busca da integração dos diferentes grupos sociais em espaços sociais existentes, mediante a valorização da diversidade cultural que formariam.

Segundo Moehlecke (2002, p. 203), o último objetivo apresentado - a valorização da diversidade cultural - é significativo:

Essa ideia de diversidade tenta conferir uma identidade positiva àqueles que antes eram definidos pela inferiorização e supõe que a convivência entre pessoas diferentes ajudaria a prevenir futuras visões preconceituosas e práticas discriminatórias.

A integração entre diferentes grupos sociais no espaço educacional acarreta a aceitação da diversidade cultural, ou seja, a admissão da diferença, da dessemelhança, e a aceitação do outro.

Sobre estas definições, Silvério (2005, p. 95) aponta que "o termo diversidade pode significar variedade, diferença e multiplicidade". A 
diferença, segundo o autor, é a qualidade do que é diferente ou aquilo que distingue uma coisa de outra, a falta de igualdade ou de semelhança. A variedade diz respeito à qualidade, atributo ou estado de algo que possui diferentes formas ou tipos que se diversificam dentro de uma classe. A multiplicidade diz respeito ao grande número ou variedade de algo. Portanto, se o diverso é signo de variedade é também expressão do múltiplo. Logo, reconhecer a diversidade significa admitir a existência múltipla e variada da população brasileira.

A adoção de um sistema de cotas para o acesso ao ensino superior público e gratuito como política de ação afirmativa surge como possibilidade concreta de inclusão de grupos, seja por critérios socioeconômicos ou étnicos. Registre-se que, no Brasil, devido às ocorrências da vinda do branco por opção e do negro como escravo durante o período de colonização e à miscigenação daí decorrente, torna-se difícil comprovar quem pertence ou não a determinado grupo étnico.

\section{Implantação no Brasil}

As políticas públicas, no Brasil, têm-se caracterizado por adotar uma perspectiva social, com medidas e ações de natureza redistributiva ou assistencial contra a pobreza, com base em concepções de igualdade. Entretanto, com a redemocratização do País, os movimentos sociais passaram a exigir uma postura proativa do poder público diante de questões que envolvem a baixa participação de grupos específicos da população em setores da atividade social, como a educação e o trabalho, como também a adoção de medidas eficazes para sua solução.

Compreender como políticas públicas podem responder a essas questões, como são construídas, e as consequências que trazem para a Nação exige a compreensão do contexto histórico brasileiro nessa área.

Aqui é preciso colocar a problemática relativa ao uso, no Brasil, do paradigma norte-americano como modelo de implantação de ações afirmativas. Há autores que entendem que a experiência dos Estados Unidos com a implantação de políticas de ações afirmativas pode servir de inspiração ao Brasil, segundo Munanga (1991, p. 46).

Ianni (2004, p. 16), por sua vez, observa que a implantação de um sistema de cotas nas universidades brasileiras tendo como modelo o padrão norte-americano tem algo de esquizofrênico e imitativo, já que, nos EUA, embora seja um dos principais paradigmas para o mundo no que tange ao sistema de cotas, o preconceito persiste. Para Margolis (2004, p. 47), parece estranho que o Brasil esteja tentando viabilizar esse sistema exatamente quando os Estados Unidos estão vacilando em seus modelos de ações afirmativas na área da educação.

Entretanto, não é possível importar simplificadamente paradigmas vivenciados por outros países cuja sociedade, valores e culturas são tão diferentes daqueles existentes no Brasil, como é o caso específico dos EUA, ainda que seja visando a solucionar problemas de 
desigualdades socioeconômicas existentes no Brasil. É necessário respeitar as peculiaridades históricas, os valores sociais e a diversidade cultural e propor medidas que se ajustem efetivamente ao caso brasileiro.

O fato é que poucos se sentem à vontade com as políticas raciais. Alguns estudiosos mais conservadores ainda descartam a ação afirmativa como um artigo exótico de importação, talvez bom para os Estados Unidos, mas pouco ou nada adequado para uma demografia racial culturalmente multicolorida, como é o caso da brasileira, conforme Margolis (2004, p. 49).

Até mesmo defensores do princípio da igualdade entre cidadãos rejeitam as cotas por medo de transformar a confusa identidade racial do Brasil em rígidas categorias legais. Há quem defenda a concepção de democracia racial como um mito e, a partir disso, negue a existência do racismo e da discriminação racial contra os negros, o que se reflete na ordem legal. Mas há também aqueles que demonstram a realidade do preconceito na questão racial, como Bastide e Fernandes (1959), que escreveram exaustivamente sobre a questão social do negro.

A questão racial revela-se um problema permanente, tanto para o indivíduo quanto para a coletividade e os cientistas sociais, filósofos e educadores. O fato é que o homem é desafiado a viver situações e interpretá-las, e muitas vezes não consegue alcançar uma explicação correta ou mesmo resolvê-las. Entende-se que, no Brasil, há racismo, e, embora seja silencioso, este fato é comprovado pelas estatísticas, especialmente as que se referem à equidade de direitos à educação e inserção no mercado de trabalho.

Apenas para ilustrar as diferenças quanto às desigualdades econômicas e educacionais, trabalho recente realizado pelos pesquisadores Maurício Cortez Reis e Anna Risi Crespo, do Ipea, reproduz o abismo salarial que separa brancos e negros no Brasil, embora com discreta diminuição no período pesquisado, conforme aponta Gois (2005, p. B-4).

\section{Tabela 1 - Desigualdade na Renda e na Educação entre Brancos e Negros} (Brasil - 1990 e 2002)

\begin{tabular}{|c|c|c|c|c|c|}
\hline $\begin{array}{l}\text { Renda/ } \\
\text { Estudo }\end{array}$ & Idade & Ano & Brancos & Negros & Diferença \\
\hline \multirow{4}{*}{$\begin{array}{c}\text { Média } \\
\text { de } \\
\text { Renda }\end{array}$} & \multirow{2}{*}{$\begin{array}{l}\text { Entre } 24 \\
\text { e } 26 \text { anos }\end{array}$} & 1990 & $\mathrm{R} \$ 753,00$ & $\mathrm{R} \$ 465,00$ & $\mathrm{~B}+62 \%$ \\
\hline & & 2002 & $\mathrm{R} \$ 611,00$ & $\mathrm{R} \$ 394,00$ & $B+55 \%$ \\
\hline & \multirow{2}{*}{$\begin{array}{l}\text { Entre } 48 \\
\text { e } 50 \text { anos }\end{array}$} & 1990 & $\mathrm{R} \$ 1,306,00$ & $\mathrm{R} \$ 567,00$ & $B+130 \%$ \\
\hline & & 2002 & $\mathrm{R} \$ 1,231,00$ & $\mathrm{R} \$ 649,00$ & B $+90 \%$ \\
\hline \multirow{4}{*}{$\begin{array}{l}\text { Média } \\
\text { de } \\
\text { Tempo } \\
\text { de } \\
\text { Estudo }\end{array}$} & \multirow{2}{*}{$\begin{array}{l}\text { Entre } 24 \\
\text { e } 26 \text { anos }\end{array}$} & 1990 & 7,9 anos & 5,9 anos & B $+2,0$ anos \\
\hline & & 2002 & 9,0 anos & 7,0 anos & B $+2,0$ anos \\
\hline & \multirow{2}{*}{$\begin{array}{l}\text { Entre } 48 \\
\text { e } 50 \text { anos }\end{array}$} & 1990 & 6,0 anos & 3,0 anos & B $+3,0$ anos \\
\hline & & 2002 & 7,8 anos & 5,4 anos & B $+2,4$ anos \\
\hline
\end{tabular}

B: Brancos.

Fonte: Gois (2005). 
Em se considerando os dados obtidos pela Pnad de 2008 que correlacionam a média dos anos de estudos ao rendimento médio mensal de todos os trabalhos (salário mínimo), tem-se a seguinte configuração, quando comparada a população de brancos, pretos e pardos:

Tabela 2 - Pessoas com 10 Anos (ou mais) de Idade, Ocupadas na Semana de Referência, com Rendimento de Trabalho, por Cor ou Raça

\begin{tabular}{c|l|l|l|}
\multicolumn{2}{|c|}{ Branca } & \multicolumn{2}{c|}{ Preta ou Parda } \\
\hline $\begin{array}{l}\text { Média de anos } \\
\text { de estudo }\end{array}$ & $\begin{array}{l}\text { Rendimento médio } \\
\text { mensal de todos } \\
\text { os trabalhos } \\
\text { (salário mínimo) }\end{array}$ & $\begin{array}{l}\text { Média de anos } \\
\text { de estudo }\end{array}$ & $\begin{array}{l}\text { Rendimento médio } \\
\text { mensal de todos } \\
\text { os trabalhos } \\
\text { (salário mínimo) }\end{array}$ \\
\hline 8,8 & 3,4 & 6,8 & 1,8 \\
\hline
\end{tabular}

Nas estatísticas relativas à educação, fator mais importante de mobilidade social, a diferença entre brancos e negros existe com significativa quantidade de estudos que comprovam a demanda por políticas corretivas raciais na educação brasileira. Como já observado anteriormente, o trabalho de Henriques (2002), pesquisador do Ipea, identifica e mapeia esta necessidade, pois a escolaridade de um jovem negro com 25 anos de idade gira em torno de 6,1 anos de estudo. Um jovem branco, por sua vez, com a mesma idade, tem cerca de 8,4 anos de estudo. O diferencial, portanto, é de 2,3 anos de escolaridade.

Tragtenberg (2003, p. 25) indica que medidas como as destinadas ao ingresso de negros no ensino superior brasileiro, seja para estudantes em cursos superiores, seja por meio de cotas para ingresso de professores na carreira docente universitária, "podem constituir-se em um contraponto ao racismo cordial existente na sociedade brasileira".

Para o mesmo autor, a política de ação afirmativa não deve ser entendida como medida contra brancos, mas como remédio transitório e paliativo enquanto durar o racismo brasileiro que gera disparidades socioeconômicas. Para ele, a construção de uma universidade mais igualitária sob o aspecto racial passa por um processo de esclarecimento dos brancos sobre a desigualdade racial reinante no Brasil.

Neste caso, é preciso considerar que o debate em torno das ações afirmativas vem se expandindo, não apenas ocupando espaço nas universidades e nos veículos de comunicação de massa, mas também por manifestações do Poder Legislativo. Com efeito, verifica-se a existência de dois grandes grupos temáticos a respeito do conteúdo dos projetos discutidos e implantados no País: a) medidas voltadas à inserção das mulheres no mercado de trabalho; b) medidas voltadas à inserção dos negros. Não se pode, contudo, desconsiderar a existência de tentativas de inserção voltadas a outros segmentos sociais, como, por exemplo, o dos idosos e dos portadores de necessidades especiais, já efetivamente implantadas no Brasil.

Quanto às políticas de promoção e implantação da igualdade sob o recorte exclusivamente racial no ensino superior levadas a termo por 
várias universidades em razão da definição de cotas para negros, há casos em que se desenvolvem projetos isolados de acesso e permanência de estudantes negros, como a Universidade Federal da Bahia (Ufba), a Uerj, a UnB e a Universidade de São Paulo (USP). Como aponta Silva (2003, p. 28), desde o segundo semestre do ano de 2002, as universidades estaduais do Rio de Janeiro, Uerj e Uenf, e a Universidade Estadual da Bahia (Uneb) vêm adotando importantes iniciativas na área específica de cotas para estudantes negros.

Além destas, a Universidade Estadual de Mato Grosso do Sul (UEMS), a Universidade Federal Fluminense (UFF), a Universidade Federal do Paraná (UFPR), a Universidade Estadual de Santa Catarina (Udesc), a Pontifícia Universidade Católica de Minas Gerais (PUC-Minas), a Universidade Federal do Amapá (Ufap), a Universidade Federal do Amazonas (Ufam), entre outras importantes instituições públicas brasileiras, também discutem internamente a implantação de ações afirmativas, sejam elas por critérios exclusivamente raciais ou não.

Apesar de todas essas iniciativas de implantação de políticas de ação afirmativa voltadas para a questão do acesso ao ensino superior brasileiro terem estimulado o debate sobre a questão da implantação do sistema de cotas para ingresso nas universidades públicas, somente no ano de 2003 a polêmica sobre a adoção ou não de cotas pelas instituições públicas brasileiras de educação superior ganhou maior contorno. Isto ocorreu em razão da publicação do resultado do vestibular da Uerj. Há também a proposta inovadora da UnB, que, pela dimensão e relevância, será tratada mais adiante.

\section{Aspectos legais e educacionais do sistema de cotas}

O princípio constitucional da igualdade encontra-se formalmente inserido como direito fundamental na Constituição Federal de 1988, em seu art. $5^{\circ}$, caput, Título II, que trata dos Direitos e Garantias Fundamentais e assim prescreve:

Todos são iguais perante a lei, sem distinção de qualquer natureza, garantindo-se aos brasileiros e aos estrangeiros residentes no País a inviolabilidade do direito à vida, à liberdade, à igualdade, à segurança e à propriedade, nos termos seguintes: [...] (Brasil, 2010).

Violar um princípio é muito mais grave do que transgredir uma norma. A desatenção a determinado princípio implica ofensa não apenas a um específico mandamento obrigatório, mas, também, a todo o sistema de comandos. É a mais grave forma de ilegalidade ou inconstitucionalidade, conforme o princípio atingido, porque representa a insurgência contra todo o sistema e a subversão de seus valores fundamentais.

Portanto, não obstante o fato de que a garantia da igualdade esteja formalmente assegurada na Constituição Federal, assim como a garantia constitucional da dignidade humana e da liberdade igual para todos, são muitos os indivíduos, independentemente de raça, cor, sexo ou credo, 
que permanecem sem ter acesso às oportunidades mínimas em termos de educação, trabalho, política, saúde, enfim, acesso ao exercício pleno da cidadania, e são deixados à margem da convivência social e da experiência de participação numa sociedade democrática.

Não basta que o Estado se abstenha de discriminar ou de tratar desigualmente, mas é necessário que atue positivamente no sentido de reduzir desigualdades sociais. Assim agindo, a concretização do princípio constitucional da igualdade apresenta-se para o poder público como objetivo que deve ser consolidado a partir de dois enfoques: proibição da discriminação e adoção de medidas concretas que reduzam a desigualdade. Portanto, a proibição da discriminação expõe-se, também, sob dois prismas: é norma voltada a todos, cujo cumprimento deve ser garantido pelo Estado, e deve contar até mesmo com o aparato repressivo penal.

\begin{abstract}
Ao se falar em igualdade na Constituição, está se dizendo duas coisas ao mesmo tempo: por um lado, impede-se o tratamento desigual e por outro se impõe ao Estado uma ação positiva no sentido de criar condições de igualdade dos indivíduos, o que necessariamente impõe um tratamento desigual dos indivíduos; [...] Neste sentido, não é ilegal discriminar positivamente com o objetivo de criar melhores condições para um determinado grupo, tradicionalmente desprivilegiado dentro da sociedade. (Domingues, 2005, p. 173).
\end{abstract}

Em artigos divulgados pela imprensa, de modo geral, houve três argumentos que nortearam a defesa do posicionamento dos autores pelo sim:

a) As ações afirmativas simbolizariam medidas compensatórias destinadas a aliviar o peso de um passado discriminatório;

b) Ação afirmativa refere-se à própria exigência de uma educação voltada para valores e para a promoção da diversidade ético-racial, considerando-se que o objetivo maior do processo educacional é o pleno desenvolvimento da personalidade humana, guiado pelo valor da cidadania, do respeito, da tolerância e da pluralidade, afirmando-se como legítimo o interesse da universidade em promover a diversidade étnico-racial;

c) Pela ordem político-social, em se pretendendo uma sociedade mais democrática, com a transformação de organizações políticas e institucionais, o título universitário ainda remanesce como um passaporte para ascensão social e para a democratização das esferas de poder, com o "empoderamento" dos grupos historicamente excluídos; assim, para ampliar o número de afrodescendentes juízes, advogados, procuradores, médicos, entre outras categorias profissionais, o título universitário é essencial.

Já os defensores do não justificaram suas opiniões com base nos seguintes argumentos:

a) É possível promover ações afirmativas sem instaurar sistemas de cotas injustos; em vez de compensar as dificuldades sociais por 
privilégios (vagas reservadas) é melhor insistir sobre critérios para avaliar corretamente o mérito dos alunos; por exemplo, os que conseguissem se destacar como os melhores alunos do secundário público teriam direito a uma consideração especial, pois os resultados sendo equivalentes, é provável que seus méritos fossem superiores aos de alunos favorecidos socialmente;

b) Os programas de ações afirmativas são paliativos e não alteram a justiça distributiva na sociedade brasileira; o modelo norteamericano não seria a solução para o contexto político brasileiro, já que poderia provocar uma discriminação "reversa";

c) Haveria a queda do padrão de qualidade das universidades públicas em decorrência do ingresso de estudantes com formação educacional deficiente, com possibilidade de marginalização e segregação dentro da própria instituição, com a formação de grupos de alunos inseridos e excluídos.

Entretanto, o mais curioso é que, de todas as opiniões dos profissionais acima mencionados, em nenhuma delas a questão foi enfocada a partir do prisma jurídico, fosse ele legal ou constitucional. Sob o ponto de vista legal, o próprio legislador, de acordo com a legislação pertinente, não utilizou para estes mecanismos as expressões ação afirmativa ou cotas, embora tenha editado diversas normas que reconhecem o direito à diferença de tratamento legal para diversos grupos.

Acrescente-se que a polêmica sobre a implantação de ações afirmativas e cotas em nosso País aumentou, particularmente quando foram editadas leis estaduais reservando vagas por cotas para candidatos negros e pardos nos processos seletivos de universidades públicas. É o caso, por exemplo, do Estado do Rio de Janeiro, relativamente às Leis Estaduais $n^{\circ} 3.524$, de 28 de dezembro de 2000, e no 3.708, de 9 de novembro de 2001, disciplinadas pelos Decretos Estaduais $n^{\circ} 30.766$, de 4 de março de 2002, e n 4.061, de 2 de janeiro de 2003.

Estas normas, em conjunto, criaram naquela unidade da Federação e pela primeira vez na educação brasileira - o que se conhece hoje como sistema de reserva de vagas no ensino superior por cotas, para candidatos pertencentes à população negra e parda, para portadores de deficiência física e para estudantes que cursaram o ensino médio em escolas públicas, reservando-se o percentual de $40 \%$ das vagas gratuitas da Uerj e da Uenf a pessoas integrantes dos referidos grupos.

\section{Universidade do Estado do Rio de Janeiro (Uerj) e Universidade Estadual do Norte Fluminense Darcy Ribeiro (Uenf)}

Apesar de todas as iniciativas de políticas de ações afirmativas direcionadas para a questão do acesso ao ensino superior público brasileiro terem alimentado o debate sobre a utilização do sistema de cotas, foi apenas em 2003, ao ser publicado o resultado do vestibular da Uerj, que 
a polêmica sobre a adoção ou não de cotas nas universidades públicas brasileiras tomou nova dimensão.

Ressalte-se que tanto a primeira norma, Lei Estadual no 3.524/2000, quanto a segunda, Lei Estadual $\mathrm{n}^{\circ}$ 3.708/2001, foram sancionadas de modo totalmente unilateral, sem qualquer participação das universidades afetadas por tais medidas. Conforme aponta Brandão (2005, p. 63), no caso da Lei no 3.708/2001, a Uerj somente foi convocada a discuti-la após sua aprovação e sanção.

O resultado dessa situação, imposta de forma absolutamente heterônoma pelo Estado do Rio de Janeiro, foi a ocorrência de cerca de 130 ações judiciais questionando a constitucionalidade da medida, sendo que 11 candidatos obtiveram a vaga por força de liminar concedida por impetração de mandado de segurança, conforme atestou o próprio vice-reitor de graduação da Uerj em palestra proferida na Universidade Estadual Paulista "Júlio de Mesquita Filho" (Unesp).

A postura do governo do Estado do Rio de Janeiro de não ouvir as sugestões das próprias instituições envolvidas, acarretando violação à autonomia das universidades, levou centenas de alunos e as próprias entidades sindicais que representam as escolas particulares do Rio de Janeiro a questionarem a legalidade da implantação do sistema de cotas, mediante ações junto ao Poder Judiciário.

A universidade, por sua autonomia, configura-se no espaço privilegiado de interlocução para proposições de reformas educacionais que possam proporcionar, desde o início da educação básica, indistintamente, a igualdade de acesso à cultura e ao conhecimento.

Dentro dos limites dessa autonomia, a universidade tem o poder de agrupar educadores, profissionais da educação e políticos visando à criação daquilo que poderia ser chamado um pacto pela melhoria da educação brasileira, isto porque iniciativas colocadas de maneira isolada, embora legítimas, podem prejudicar o debate sobre a efetividade dessas medidas de ações afirmativas.

O fato é que, no caso do sistema de reserva de vagas implantado no Estado do Rio de Janeiro em razão dos percentuais fixados nas leis mencionadas, o governo daquele Estado finalmente tomou a iniciativa de rever a própria legislação estadual sobre o sistema de cotas implantado, iniciando uma discussão sobre a reavaliação do sistema com representantes das instituições envolvidas e demais entidades.

Em razão desta revisão, foi sancionada em 4 de setembro de 2003 mais uma norma, a Lei Estadual $n^{\circ} 4.151 / 2003$, instituindo nova disciplina sobre o sistema de cotas para ingresso nas universidades públicas estaduais, cujo teor acrescentou que a cota só se aplica aos estudantes que comprovem efetiva carência econômica; ou seja, um candidato que se declare afrodescendente e não for carente não terá direito à cota étnica.

A discussão sobre o caso da Uerj e da Uenf tem levado educadores ao debate, especialmente por meio de artigos publicados na mídia impressa, com foco na permanência do aluno cotista na universidade. O problema a ser enfrentado pelas instituições é a falta de condições para o aluno 
manter-se financeiramente, necessitando também de outros recursos para acompanhar, em nível de igualdade, os demais alunos de seu curso.

Além do aspecto financeiro e social, sob o ponto de vista pedagógico, seriam necessários investimentos e condições de acompanhamento dos alunos que ingressam pelo sistema de cotas, pois grande parte deles necessita de reforço em disciplinas específicas. Neste aspecto, a experiência da Pontifícia Universidade Católica do Rio de Janeiro (PUC-Rio) é citada por especialistas como referência a ser seguida pelo fato de ela ter implantado uma política que visa a impedir que o aluno carente fique num nível pedagógico muito abaixo dos demais ou abandone seu curso por dificuldades financeiras.

A criação de condições de acesso por via de políticas de ações afirmativas para que determinados grupos sociais e/ou raciais ingressem nas universidades, seja mediante a implantação de um sistema de cotas, seja por meio de outras modalidades, deve vir acompanhada de um programa sistemático de apoio acadêmico. O debate interno torna-se imprescindível às universidades públicas promotoras de ações inclusivas, com vista a adotar condições efetivas de permanência para que os estudantes beneficiados não engrossem as estatísticas de evasão do ensino superior brasileiro.

\section{Universidade de Brasília (UnB)}

Em 1985, em plena fase final do processo de redemocratização do País, a UnB começou a esboçar algumas tentativas de modificar a realidade do perfil de seus estudantes universitários, já que, naquele ano, quase 90\% de seus alunos eram egressos de escolas mantidas pela iniciativa privada, conforme aponta Belloni (2003, p. 463). Segundo ela, uma das propostas visando à modificação daquele quadro estabelecia uma reserva de parte das vagas disponíveis por cotas no vestibular para egressos da escola pública, com acompanhamento acadêmico para superação de eventuais insuficiências detectadas. Outra proposta visava à implantação de um sistema de avaliação em cada uma das séries do ensino médio da escola pública, para melhorar a competitividade daqueles alunos e a qualidade dos ingressantes na universidade.

Em 1996, segundo Carvalho (2005), a Secretaria dos Direitos da Cidadania do Ministério da Justiça promoveu um seminário internacional na UnB para discutir a discriminação racial no Brasil. Naquela oportunidade, em que se congregaram renomados especialistas brasileiros e norte-americanos, foram discutidas as diferenças entre o racismo brasileiro e o norte-americano e a possibilidade de implantação de um conjunto de ações afirmativas visando à reparação da exclusão sofrida pelos negros no Brasil.

Foi no ano de 2001, entretanto, que os debates sobre as ações afirmativas na Universidade de Brasília ganharam intensidade, isto porque, após a Conferência Mundial de Combate ao Racismo, Discriminação 
Racial, Xenofobia e Intolerância Correlata, realizada em Durban, na África do Sul, a relatora da comitiva brasileira naquele evento, Edna Roland, esteve na UnB.

Conforme aponta Moura (2004), a discussão interna sobre cotas na Universidade de Brasília ecoou num amplo debate nacional e internacional sobre as ações afirmativas como um todo e sobre a necessidade de incorporá-las à área de educação, especialmente ao ensino superior.

Percebe-se, entretanto, que o processo de implantação da integração social, étnica e racial junto a essa universidade pública federal foi fruto de longo debate interno, realizado em conjunto com os corpos docente e discente, promovido pelo Núcleo de Estudos Afro-Brasileiros (Neab/UnB), coordenado, à época, pelo professor Nelson Inocêncio, pelo movimento negro estudantil (EnegreSer), vinculado ao núcleo, pelos pesquisadores do Departamento de Antropologia da UnB, José Jorge de Carvalho e Rita Laura Segato, pelo movimento estudantil Diretório Central dos Estudantes (DCE) e pelo Centro Acadêmico da UnB. Nesse processo, contou-se também com o apoio de lideranças indígenas, da Fundação Nacional do Índio (Funai) e do próprio Ministério da Educação (MEC).

Em 2003, após inúmeras reuniões, seminários e visitas de estudiosos ligados ao tema, a UnB finalmente aprovou, por intermédio de seu Conselho de Ensino, Pesquisa e Extensão (Cepe), um programa de inclusão com o objetivo de democratizar o acesso à universidade para os setores populacionais mais vulneráveis, denominado Plano de Metas para Integração Social, Étnica e Racial.

O referido plano, aprovado por 24 votos a favor, um contra e uma abstenção pelo Conselho de Ensino, Pesquisa e Extensão (Cepe/UnB), na reunião de 6 de junho de 2003, visa a atender à necessidade de gerar, na Universidade de Brasília, uma composição social, ética e racial capaz de refletir a realidade social do Distrito Federal e a diversidade da sociedade brasileira como um todo. Nota-se que o objetivo dessa iniciativa teve como alicerce pesquisas realizadas pela própria universidade e os índices apresentados no documento Síntese dos Indicadores Sociais (IBGE, 2008), indicando que apenas 4,4 \% dos estudantes universitários brasileiros são negros e 3,2 \%, pardos.

As palavras "acesso", "permanência" e "apoio", conforme entendimento do plano, representam sua estrutura, como se delas dependesse o sucesso da política de ações afirmativas. Não basta propiciar o acesso, pois é necessário conferir, após o ingresso, igualdade de condições de permanência do estudante no ensino superior público, já que dificilmente os indivíduos deste contingente estão em igualdade de condições no que tange à questão socioeconômica. Do contrário, teria a universidade que admitir o considerável risco de evasão desse grupo de beneficiados por falta de condições sociais, econômicas e intelectuais.

Além disso, quanto à permanência, a UnB, durante a implementação do plano, estabeleceu diálogo com entidades do governo federal, especialmente com a Fundação Cultural Palmares, visando a organizar mecanismos de vinculação dos estudantes ingressantes pelo sistema de 
cotas em atividades de pesquisa e extensão relacionadas à inclusão social e à temática racial.

Também favoreceu o objetivo da permanência do estudante contemplado pelo sistema de cotas o programa de acompanhamento acadêmico e psicossocial, no sentido de garantir apoio para superação de eventuais dificuldades.

O plano prevê ainda que a UnB promoverá um conjunto concomitante de ações de apoio, objetivando a melhoria da qualidade da educação nas escolas públicas da região de baixa renda do Distrito Federal, tanto no aumento do nível de aprendizagem das crianças, jovens e adultos do ensino fundamental e médio quanto na avaliação do trabalho docente.

Este conjunto de medidas educacionais dá ao plano da UnB um caráter inclusivo na sua plenitude, pois da discussão interna em seu colegiado superior nasceram as ideias e os ideais de um projeto baseado em ações afirmativas. A luta pela inclusão no ensino superior público é necessária, mas não suficiente, para garantir a permanência dos beneficiados por medidas compensatórias.

Com relação aos critérios do vestibular da UnB, conforme esclarece Moura (2004, p. 227), no edital do processo seletivo de 2004, a UnB destinou $20 \%$ das vagas de seus cursos superiores para a concorrência entre candidatos negros. O edital estabelece que haja a autodeclaração, pois no momento da inscrição o candidato terá a faculdade de autodeclarar-se negro ou pardo, segundo a classificação do IBGE, e, depois, optar pelo sistema de cotas e requerer sua inscrição no processo. Neste ato, os candidatos ao sistema de reserva de vagas por cotas serão, entretanto, fotografados individualmente, para arquivamento e posterior homologação do pedido de inscrição.

Quanto aos critérios de autodeclaração e de ingresso, Carvalho (2005) optou, na proposta original de cotas por ele elaborada e encaminhada ao Conselho de Ensino, Pesquisa e Extensão (Cepe/UnB), pela autodeclaração como critério suficiente para que um candidato se inscrevesse no vestibular na UnB por cotas, porque não parecia adequado, durante todos os anos de debate da proposta, oferecer as vagas das cotas para negros e pardos. Conforme argumentou o autor, pardo é um termo que carrega ambiguidade, pois muitas pessoas de pele morena, não discriminadas racialmente, podem declarar-se pardas.

Porém, contra o juízo dos dois pesquisadores em questão, a comissão de implantação das cotas da UnB reintroduziu na ficha de inscrição do vestibular exatamente aquilo que ambos haviam evitado após longa reflexão: a identificação através das categorias do IBGE de pretos e pardos.

Desta forma, a ficha de inscrição do primeiro vestibular das cotas da UnB ficou do seguinte modo: o estudante respondia se era preto ou pardo; em seguida, indicava se se considerava negro. Caso respondesse afirmativamente às duas questões, respondia, então, se queria ou não participar do sistema de cotas. Porém, para evitar fraudes, a Comissão decidiu utilizar o mesmo sistema que acabava de ser implantado no vestibular da Universidade Estadual do Mato Grosso do Sul (Uems): o teste 
das fotos. Desta forma, todo candidato que optar pelas cotas tem de posar para a foto. Uma comissão foi formada para avaliar as fotografias e validar ou rejeitar a inscrição dos candidatos pelo sistema de cotas a partir da análise dos seus fenótipos.

Ficou previsto que a Comissão de Homologação da UnB, além de examinar os pedidos de inscrição, seria instância recursal para análise de eventuais solicitações de esclarecimentos ou de reforma de decisões. Os candidatos receberiam, junto com sua confirmação de inscrição, a informação de terem sido inscritos pelo sistema de cotas ou pelo sistema universal (tradicional).

Pelo exposto e considerando os critérios adotados pela UnB para implantação de um sistema de cotas, constata-se que o modelo apresentado é inédito em relação a outras políticas de ações afirmativas das demais universidades públicas brasileiras. Além disso, tem o mérito do estabelecimento de uma meta temporal que, uma vez alcançada, poderá fundamentar reavaliações, ajustes e demais ações corretivas.

Esta análise sobre o programa da UnB permitiu entendê-lo como plano que vai ao encontro daquilo que Silva (2003, p. 30) definiu como a "trilogia acesso, permanência e sucesso". Esta afirmação é imperativa quando se trata de sistema de cotas e de política de ação afirmativa para as minorias na universidade.

De qualquer forma, a grande tarefa de discutir o tema caberá aos educadores, já que a Educação, além de escancarar a convicção de que a mudança é possível, como diria Paulo Freire, também "é um ato de amor, por isso, um ato de coragem. Não pode temer o debate. A análise da realidade. Não pode fugir à discussão criadora, sob pena de ser uma farsa" (Freire, 2003, p. 104).

Assim, para os educadores, o grande desafio é a discussão, o diálogo, a criação pela comunicação visando à consolidação dessas políticas de ações afirmativas voltadas ao acesso à educação neste imenso e desigual país, na busca do direito real e não formal de uma educação para todos.

\section{Conclusão}

Caberá aos profissionais da educação, pedagogos, juristas e governantes o desafio de discutir, à exaustão, todas as espécies de ações afirmativas para além do debate sobre as cotas para grupos específicos no ensino superior, de modo que as minorias excluídas do processo educacional brasileiro passem a ter melhores condições de acesso também à educação básica.

Entende-se que países marcados historicamente por políticas separatistas ou por adotarem modelos de organização social com base em privilégios têm de enfrentar a discussão sobre medidas compensatórias para grupos minoritários ou excluídos, sob pena de, caso não o façam, estarem construindo lentamente sociedades preconceituosas e discriminatórias.

No Brasil, embora exista o impedimento legal de práticas discriminatórias, conforme dispõe o art. $5^{\circ}$ da Constituição Federal de 1988, o País 
possui flagrantes desigualdades entre brancos e negros, conforme se pode constatar pelos dados apresentados neste texto. Ocorre que as diferenças existentes nos níveis de educação e renda entre brancos e negros vão se disseminando silenciosamente de geração em geração. Os indicadores mostram que os negros sobrevivem numa realidade mais perversa do que os brancos, com salários menores, menos tempo de escolaridade, desemprego maior, mais exposição à violência. A presença dos negros na universidade é destacadamente menor do que a de brancos. Daí a necessidade de medidas compensatórias que visem à diminuição dessas diferenças.

Entre essas políticas estão as denominadas ações afirmativas, que, como demonstramos neste artigo, são iniciativas essenciais para a promoção do princípio constitucional da igualdade. Com efeito, entre as ações afirmativas, o sistema de cotas pode ser aplicado ao modelo universitário atual visando a garantir parcela das vagas nas universidades públicas para candidatos negros ou pobres.

O fato é que se faz parte de uma sociedade diferenciada e complexa, em que a discriminação racial ocorre na medida em que pessoas são segregadas ou excluídas do acesso à educação superior não por serem negras, mas por serem economicamente desfavorecidas ou por graves deficiências em sua formação na educação básica.

Se a maioria dos pobres é composta de cidadãos afrodescendentes, a exclusão começa antes mesmo de seu nascimento. Trazê-los para o ensino superior pode minimizar desigualdades sociais históricas e possibilitar a plena participação social e econômica no País.

No Brasil, como não se tem combatido efetivamente a principal causa de toda forma de exclusão, qual seja, a deficiência durante o processo de formação educacional de nossas crianças e jovens, é forçoso reconhecer que o critério de seleção ao ensino superior baseado somente no mérito para selecionar estudantes universitários pode proporcionar a perpetuação das desigualdades de origem escolar.

Sem ferir o princípio constitucional, as políticas de ações afirmativas podem substituir o conceito de igualdade de oportunidades por um conceito de igualdade de resultados entre cidadãos pertencentes a determinados grupos, pois a proibição legal à discriminação racial consolidou a igualdade entre todos.

Neste sentido, entende-se que as cotas podem ser o meio mais eficaz de democratizar o acesso ao ensino superior, desde que seja respeitada a autonomia da universidade. Isto é possível se houver a discussão aberta sobre a questão no seio da comunidade acadêmica, local privilegiado de produção e difusão do conhecimento e de decisões sobre as necessidades da sociedade.

Há que se concordar, também, que a implantação de um sistema de cotas numa instituição pública de ensino superior deve passar por amplo e profundo debate no âmbito da própria universidade, com a participação representativa da comunidade e dos movimentos sociais.

Tendo-se o caso brasileiro como exemplo de implantação do sistema de cotas apresentado e analisado nesta pesquisa, ou seja, a lei estadual 
sobre cotas para as universidades do Estado do Rio de Janeiro (Uerj e Uenf), vê-se que a medida legal adotada, em que o Estado do Rio de Janeiro impôs, de maneira heterônoma e unilateral, a regra do sistema de cotas às duas universidades estaduais, sem qualquer discussão nem debate prévio com a respectiva comunidade acadêmica, resultou em sérios conflitos entre estudantes, universidade e o Poder Judiciário.

Por outro lado, o Plano de Metas para Integração Social, Étnica e Racial da Universidade de Brasília (UnB), fruto de inúmeras audiências internas e debates com docentes, discentes e representantes de movimentos sociais e de grupos-alvo de políticas de ações afirmativas, visou não somente ao ingresso do estudante negro e carente na universidade, mas também às suas condições de permanência. Desta maneira, a UnB exercitou plenamente sua atribuição legal de autonomia universitária, ao instituir o próprio sistema de cotas sem interferência estatal.

Neste aspecto, sempre haverá quem condene o sistema de cotas baseado na condição étnico-racial, posto que estará transgredindo um princípio constitucional - o da igualdade -, além de contrariar o mérito individual, incentivar atitudes racistas, estigmatizar pessoas ou grupos beneficiados pelas medidas e ferir os direitos daqueles que passam para a condição de excluídos em decorrência de sua implantação.

Considerando, contudo, que existem desigualdades educacionais entre brancos e negros no sistema universitário brasileiro, vê-se como necessárias ações objetivas e a discussão amadurecida para que se possa corrigir ou diminuir prejuízos históricos causados às minorias pelo modelo educacional.

Essas medidas, porém, devem vir acompanhadas do mais amplo debate dentro da universidade pública, de modo a preservar sua autonomia, a fim de que a própria universidade, no exercício dessa discricionariedade, possa contemplar sua diversidade e as características socioeconômicas de seu entorno, seja com base nos indicadores municipais ou do Estado onde se localiza.

Do ponto de vista internacional, as experiências de outros países que conviveram ou convivem com o racismo podem servir de exemplo para o Brasil, desde que sejam observados a diversidade e o multiculturalismo. As práticas positivas e negativas vivenciadas por outras nações podem auxiliar na construção de uma solução brasileira própria, considerando que não há um modelo pronto para enfrentar as questões de desigualdade social entre brancos e negros.

Os indicadores brasileiros demonstram que se está longe de igualar, em curto prazo, a posição social e educacional entre brancos e negros. Parafraseando a célebre citação de Rui Barbosa, quando se referiu à questão da isonomia constitucional, ainda se tratam igualmente as pessoas desiguais, quando se deveriam tratá-las de modo desigual, na proporção de suas desigualdades. Desta forma, o estudante branco pobre e o negro pobre não são iguais, pois o primeiro é discriminado pelo fator socioeconômico e o segundo é discriminado duas vezes, pela condição socioeconômica e racial. 
As cotas, nestas condições, vão propiciar vantagens aos negros, mas não aos negros pobres, pois estes vivem à margem dos limites da pobreza e, na prática, sequer sonham com o curso superior. Os beneficiados, de fato, serão os negros que se misturam aos brancos no tecido social da classe média brasileira baixa e que, por práticas discriminatórias associadas às deficiências na formação básica, acabam excluídos pelo funil do vestibular tradicional baseado no mérito.

Por tudo isso se justifica a adoção de políticas preferenciais, fundamentais para a promoção da igualdade, desde que estas garantam condições materiais e formais para superar efeitos do racismo e que sejam destinadas a grupos potencialmente excluídos, no sentido de recuperar perdas e reparar injustiças historicamente constatadas entre brancos e negros no processo de desenvolvimento da sociedade brasileira.

Contudo, a importância dessa aceleração justifica o caráter temporário e transitório dessas políticas públicas, que não se podem apresentar como permanentes. Se alcançadas as metas previamente definidas e os objetivos de inclusão social, tais políticas esvaziam-se em suas razões de existência e não mais se sustentam juridicamente. O tempo possível para duração de um possível sistema de cotas deve também ser incluído na agenda do debate nacional sobre a questão com as devidas ponderações e zelo, para que não prospere o aparecimento de interesses de grupos visando a eternizá-lo. A proposta das cotas, desta forma, é colocada como instrumento capaz de provocar resultados positivos no processo de diminuição das injustiças a que foram e são submetidos os menos favorecidos no Brasil.

Outro olhar que se coloca sobre o sistema de cotas não se restringe ao ingresso de estudantes negros e pardos nas universidades públicas, mas à permanência deste público nos cursos superiores. Questiona-se que este fato poderia levar a uma degradação da qualidade do ensino ministrado, pois estes alunos não tiveram o mesmo preparo intelectual e escolar que os brancos durante o ensino fundamental e médio, o que acarretaria o crescimento da evasão por falta de condições financeiras para permanecer na universidade.

Quanto à primeira dificuldade indicada - queda na qualidade do ensino -, há discórdia, pois acredita-se que seja a universidade a principal instituição capaz de eliminar as deficiências de alunos oriundos das escolas públicas de educação básica, já que, por intermédio de propostas de acompanhamento e formação complementar, é possível reparar deficiências da formação básica. Os estudantes negros ou pardos que ingressarem pelo sistema de cotas em universidades públicas de boa qualidade receberão conhecimento cultural e científico que os acompanhará na batalha por ascensão social e profissional.

Mesmo que certas práticas veladas de discriminação permaneçam no seio da sociedade brasileira, os negros ou pardos que tiverem acesso à educação superior plena por meio do sistema de cotas conquistarão uma mobilidade social jamais antes conhecida.

Com relação à possível evasão dos cursos superiores por dificuldades financeiras de autossustentação, tome-se como exemplo o sistema adotado 
pela Universidade de Brasília (UnB), apresentado nesta pesquisa. Naquela instituição pública foram adotados programas visando à permanência do estudante ingressante pelo sistema de cotas, desde o apoio acadêmico e psicopedagógico até programas de manutenção financeira para alunos em situação de carência econômica.

A UnB encontrou caminhos alternativos de viabilização de seu plano de metas, e hoje é considerada excelente paradigma no que se refere à implantação de um sistema de cotas para candidatos negros, pardos e indígenas. Entende-se que a instituição exerceu de forma exemplar sua autonomia, debatendo, ouvindo propostas, revendo conceitos, aceitando argumentos e decidindo no voto, democraticamente, por seu órgão colegiado superior, sobre o caminho mais adequado a seguir.

A proposta da adoção de políticas de ações afirmativas, criando um sistema de reserva para as disputadas vagas das universidades públicas brasileiras por intermédio de cotas para estudantes negros, pardos e indígenas, tem o mérito de expor ao debate público o grave problema do racismo, do mito da democracia racial - embora esta já esteja desmistificada - e da desigualdade educacional entre brancos e negros no País.

Sem a pretensão de finalizar aqui o debate sobre o sistema de cotas nas universidades públicas brasileiras, acredita-se que o presente texto possa contribuir para o aperfeiçoamento do ensino superior, tanto no sistema federal quanto nos Estados e municípios, pela discussão franca e aberta sobre um problema secular que o Estado e a sociedade carregam sobre si - a falta de medidas que promovam a justiça social.

É praticamente impossível separar os argumentos em favor das cotas de um lado e os contrários a elas de outro. Entretanto, a proposta das cotas pode propiciar a integração de grupos étnicos e sociais afetados historicamente em espaços da universidade brasileira em que a presença de brancos até então prevalecia.

O que se ressalta e se considera um salto para o País é o desencadeamento de um processo em que a elite passe a contar com a contribuição e a participação significativa de cidadãos pertencentes a grupos étnico-raciais injustiçados no contexto da construção da sociedade brasileira, no qual não haverá limitações de acesso ao saber e ao poder, dando efeito à consciência de uma democracia em que a participação da população menos favorecida seja assumida de maneira equilibrada e duradoura.

Há que se considerar, também, que a adoção de cotas para inclusão de indivíduos historicamente discriminados na universidade pública brasileira deve ser debatida e decidida internamente pelos órgãos colegiados legalmente constituídos, em vez de estabelecidas arbitrariamente por força de lei, cujo teor possa estar desprovido de experiências e práticas acadêmicas. A autonomia constitucional impõe-se como fundamental nas decisões que possam influenciar nos caminhos e no futuro da universidade.

Por derradeiro, destaque-se que, na discussão sobre reserva de vagas nas universidades públicas brasileiras por sistema de cotas, deve-se lembrar que pessoas discriminadas, independentemente de sua condição socioeconômica, precisam ser incluídas como as principais beneficiárias 
dessas medidas. Os indicadores mostram que o preconceito, no Brasil, é um problema presente e ainda longe de uma solução democrática para a diminuição de desigualdades que perduram há décadas.

Para atingir a necessária mudança na equidade educacional, é indispensável que se altere o mapa da exclusão social no Brasil, buscando uma condição básica: o despertar de consciências dos cidadãos.

\section{Referências bibliográficas}

BASTIDE, Roger; FERNANDES, Florestan. Brancos e negros em São Paulo: ensaio sociológico sobre aspectos da formação, manifestações atuais e efeitos do preconceito de cor na sociedade paulistana. 2. ed., rev. e ampl. São Paulo: Ed. Nacional, 1959. (Coleção Brasiliana).

BELLONI, Isaura. Política de ação afirmativa para a democracia e a igualdade. In: MORHY, Lauro (Org.). Universidade em questão. Brasília: UnB, 2003. v. 1, p. 455-468.

BRANDÃO, Carlos da Fonseca. As cotas na universidade pública brasileira: será esse o caminho? Campinas: Autores Associados, 2005. v. 92. (Coleção Polêmicas do Nosso Tempo).

BRASIL. Constituição de 1988. Constituição da República Federativa do Brasil, de 05 de outubro de 1988. 15. rev. ampl. e atual. São Paulo: Revista dos Tribunais, 2010. (Atualizada até a Emenda Constitucional $n^{\circ}$ 62/2009).

BRASIL. Projeto de Lei no 3.627, de 28 de abril de 2004. Institui Sistema Especial de Reservas de Vagas para estudantes egressos de escolas públicas, em especial negros e indígenas, nas instituições públicas federais de educação superior. Disponível em: < http:// portal.mec.gov.br/arquivos/pdf/ref_projlei3627.pdf>. Acesso em: 8 abr. 2011.

. Projeto de Lei n 7.200/2006, de 10 de abril de 2006.

Estabelece normas gerais da educação superior, regula a educação superior no sistema federal, altera as Leis $n^{\text {os }} 9.394$, de 20 de dezembro de 1996; 8.958, de 20 de dezembro de 1994; 9.504, de 30 de setembro de 1997; 9.532, de 20 de dezembro de 1997; 9.870, de 23 de setembro de 1999. Disponível em: < http://www.camara.gov.br/sileg/ integras/402692.pdf>. Acesso em: 11 abr. 2011.

BRASIL. Instituto Nacional de Estudos e Pesquisas Educacionais Anísio Teixeira (Inep). Resumo técnico: censo da educação superior de 2009. Brasília: Inep/MEC, 2010. Disponível em: <http://www.inep.gov.br/ 
download/superior/censo/2009/resumo_tecnico2009.pdf>. Acesso em: 2 abr. 2011.

CARVALHO, José Jorge de. Inclusão étnica e racial no Brasil: a questão das cotas no ensino superior. São Paulo: Attar, 2005.

DOMINGUES, Petrônio. Ações afirmativas para negros no Brasil: o início de uma reparação histórica. Associação Nacional de PósGraduação e Pesquisa em Educação, n. 29, p. 164-176, 2005.

DWORKIN, Ronald. Uma questão de princípio. 2. ed. São Paulo: Martins Fontes, 2001.

FREIRE, Paulo. Educação como prática da liberdade. 24. ed. São Paulo: Paz e Terra, 2003.

GOIS, Antonio. Cai diferença de renda entre brancos e negros. Folha de S. Paulo. São Paulo, 25 set. 2005. Disponível em: < http://www1.folha.uol. com.br/folha/dinheiro/ult91u100731.shtml>. Acesso em: 25 set. 2010.

GOMES, Joaquim Barbosa. O debate constitucional sobre as ações afirmativas. In: SANTOS, Renato Emerson dos; LOBATO, Fátima (Orgs.). Ações afirmativas: políticas públicas contra as desigualdades raciais. Rio de Janeiro: DP\&A, 2003.

. Ação afirmativa \& princípio constitucional da igualdade: o direito como instrumento de transformação social - a experiência dos EUA. Rio de Janeiro: Renovar, 2001.

HENRIQUES, Ricardo. Desigualdade racial no Brasil: evolução das condições de vida na década de 90. Rio de Janeiro: Ipea, 2002.

IANNI, Octávio. O preconceito racial no Brasil. Estudos Avançados, São Paulo, v. 18, n. 50, p. 6-30, jan./abr. 2004.

INSTITUTO BRASILEIRO DE GEOGRAFIA E ESTATÍSTICA (IBGE). Síntese de indicadores sociais: uma análise das condições de vida da população brasileira. Estudos e pesquisas: informação demográfica e socioeconômica no 23. Rio de Janeiro: IBGE, 2008. Disponível em: < http://www.ibge. gov.br/home/estatistica/populacao/condicaodevida/indicadoresminimos/ sinteseindicsociais2008/indic_sociais2008.pdf> . Acesso em: 2 abr. 2011.

JAPIASSÚ, Hilton; MARCONDES, Danilo. Dicionário básico de Filosofia. 3. ed. Rio de Janeiro: Zahar, 1996.

MARGOLIS, Mac. Cotas e cultura: ações afirmativas em tempos de dúvida. In: PAIVA, Angela Randolpho (Org.). Ação afirmativa na 
universidade: reflexão sobre experiências concretas Brasil-Estados Unidos. Rio de Janeiro: PUC-Rio, 2004. p. 45-51.

MENEZES, Paulo Lucena de. A ação afirmativa (Affirmative Action) no direito norte-americano. São Paulo: Revista dos Tribunais, 2001.

MOEHLECKE, Sabrina. Ação afirmativa: história e debates no Brasil. Cadernos de Pesquisa, São Paulo, n. 117, p. 197-217, nov. 2002.

MOURA, Dione Oliveira. Plano de metas para a integração social, étnica e racial da UnB: relato da comissão de implementação. In: BERNARDINO, Joaze; GALDINO, Daniela (Orgs.). Levando raça a sério: ações afirmativas e universidade. Rio de Janeiro: DP\&A, 2004. p. 217-228.

MUNANGA, Kabengele. Ação afirmativa em benefício da população negra. Universidade e Sociedade, Brasília, v. 1, n. 1, p. 46-52, fev. 1991.

RIO DE JANEIRO (Estado). Decreto Estadual no 4.151, de 4 de setembro de 2003. Institui nova disciplina sobre o sistema de cotas para ingresso nas universidades públicas estaduais. 2003. Disponível em: < http://alerjln1.alerj.rj.gov.br/contlei.nsf/ b24a2da5a077847c032564f4005d4bf2/e50b5bf653e6040983256d9c0 0606969?OpenDocument>. Acesso em: 11 abr. 2011.

. Decreto Estadual no 30.766, de 4 de março de 2002.

Disciplina o sistema de cota para negros e pardos no acesso à Universidade do Estado do Rio de Janeiro e à Universidade Estadual do Norte Fluminense e dá outras providências. Disponível em: < http:// www.imprensaoficial.rj.gov.br/portal/> . Acesso em: 13 abr. 2011.

. Lei Estadual no 3.524, de 28 de dezembro de 2000. Dispõe sobre os critérios de seleção e admissão de estudantes da rede pública estadual de ensino em universidades públicas estaduais. Disponível em: < http://www.imprensaoficial.rj.gov.br/portal/> . Acesso em: 13 abr. 2011.

. Lei Estadual no 3.708, de 9 de novembro de 2001. Institui cota de até 40\% (quarenta por cento) para as populações negra e parda no acesso à Universidade do Estado do Rio de Janeiro e à Universidade Estadual do Norte Fluminense. Disponível em: < http://www.jusbrasil. com.br/legislacao/90840/lei-3708-01-rio-de-janeiro-rj>. Acesso em: 25 set. 2010.

. Lei $n^{\circ} 4.061$, de 2 de janeiro de 2003. Dispõe sobre a reserva $10 \%$ das vagas em todos os cursos das universidades públicas estaduais a alunos portadores de deficiência. 2003. Disponível em: <http://app.crea-rj.org.br/portalcreav2midia/documentos/leie4061. pdf>. Acesso em: 11 abr. 2011. 
SANTOS, Julio Teles dos. Dilemas atuais das políticas para os afrobrasileiros: ação afirmativa no Brasil dos anos 60. In: BACELAR, J.; CARDOSO, C. (Orgs.). Brasil: um país de negros? Rio de Janeiro: Pallas, 1999. p. 209-212.

SILVA, Cidinha da. Ações afirmativas em educação: um debate para além das cotas. In: (Org.). Ações afirmativas em educação: experiências brasileiras. São Paulo: Summus, 2003. p. 17-38.

SILVÉRIO, Valter Roberto. Políticas raciais compensatórias: o dilema brasileiro no século XXI. Petrópolis: Abong, 2005. p. 95.

SOWELL, Thomas. Ação afirmativa ao redor do mundo: estudo empírico. Rio de Janeiro: UniverCidade, 2004.

TAYLOR, Charles. Multiculturalismo. Lisboa: Instituto Piaget, 1998.

TRAGTENBERG, Marcelo Henrique Romano. A luta contra o racismo no Brasil e o movimento docente. Universidade e Sociedade, Brasília, v. 12, n. 29, p. 19-28, 2003.

Celia Maria Haas, doutora em Educação (Currículo) pela Pontifícia Universidade Católica de São Paulo (PUC-SP), é professora titular do Programa de Mestrado em Educação da Universidade Cidade de São Paulo (Unicid) e coordenadora da Escola de Educação da Universidade Municipal de São Caetano do Sul (USCS).

celiamhaas@uol.com.br

Milton Linhares, doutor em Ciências pela Universidade de São Paulo (USP), é conselheiro do Conselho Nacional de Educação (CNE) do Ministério da Educação (MEC) e do Conselho Estadual de Educação de São Paulo (CEE). miltonsp9@uol.com.br

Recebido em 20 de abril de 2011. Aprovado em 18 de abril de 2012. 